\title{
Microwave Heating-Dependent Properties of Tilapia (Oreochromis niloticus) and Catfish (Clarias gariepirus)
}

\section{Burubai $W^{*}$ and Amber B}

Department of Agricultural \& Environmental Engineering, Faculty of Engineering, Niger Delta University, P.M.B. 071, Wilberforce Island, Yenagoa, Bayelsa State, Nigeria

\begin{abstract}
Some microwave heating-dependent properties of Tilapia and Catfish, as a function of moisture content and frequency, were studied, using the capacitance technique. Results show that electrical resistance, dielectric constant $\left(\varepsilon^{1}\right)$ and dielectric loss factor $\left(\varepsilon^{11}\right)$ were all influenced by moisture and frequency changes. For Tilapia, dielectric constant and dielectric loss factors increased from 2.19 to 10.97 and 0.10 to 23.42 for respective moisture levels of $6.2 \%$ to $16.5 \% \mathrm{db}$. Similarly, for catfish, dielectric constant and loss factors changed from 1.35 to 54.15 and 75.28 to 168.38 for corresponding increase in moisture levels of $6.2 \%$ to $16.5 \%$ $\mathrm{db}$.
\end{abstract}

Keywords: Dielectric constant; Loss factor; Electrical resistance; Moisture content; Frequency

\section{Introduction}

Fish as a source of animal protein in the human diet, plays a significant role in the overall well-being of mankind. Generally, Catfish (Clarias gariepinus) and Tilapia (Oreochromis niloticus) are the most common and widely consumed species of fish in the southern part of Nigeria (Niger Delta Region). The nutrient content of farm-raised and natural catfish and tilapia muscles has been published in various research articles over the years. Comprehensive data on the proximate composition of both catfish and tilapia is shown in Table 1.

In spite of the nutritional value of the two fish species, their availability is seasonal and, in recent years, their demand tends to surpass the supply due to poor post-harvest handling, increase in population and lack of processing and storage facilities. According to FAO report [1], the estimated fish demand for Nigeria in 1994 was pegged at 1,139,883 tonnes based on population figure of 94,986,044 and per capita consumption of $12.0 \mathrm{~kg}$, which was the globally accepted rate for normal and healthy growth. In that year, however, only 280,307 tonnes of fish were produced, pointing to a short fall of 859,526 tonnes due to postharvest losses [1] (Figure 1).

It is against this backdrop that diverse preservation techniques have been employed to process and preserve both species of fish at their peak periods and for stored for the off-seasons. These include sun drying, smoking, cold storage (refrigeration), solar drying and microwave drying. However, literature reveals that the various forms of preservation have their attendant effects on the nutritive and organoleptic characteristics of fish [2-4]. Ogbonnaya and Ibrahim [5], however, reported that amongst the different preservation methods, microwave drying is the best. According to them, microwave drying not only increases the shelf-life of the product, but retains more nutrient than other methods.

This best microwave heating (drying) process is governed by certain material heating properties called dielectric properties. These include dielectric constant, $\varepsilon^{1}$ and dielectric loss factor. These two factors measure the ability of the material to interact with the electric field of the microwaves. Thus, the dielectric constant is a measure of the food materials ability to store electromagnetic energy, whereas loss factor is the materials ability to dissipate electromagnetic energy which results in heating. These dielectric properties for biological materials depend on moisture content, frequency, temperature and salt content. It is on this note that Mahmoud and Rezza [6] studied the effect of moisture content on the dielectric properties of pea using the capacitance technique. They observed that both properties increased positively with moisture increase. Several researchers have also published articles on the dielectric properties of different agricultural and food products [7-10].

However, there is dearth of information on the dielectric properties of Catfish and Tilapia to aid microwaves drying operations. It is therefore the objectives of this study to determine the effects of moisture content and frequency on the dielectric constants and loss factors of Catfish and Tilapia muscles.

\begin{tabular}{|c|c|c|}
\hline Proximates & Tilapia & Catfish \\
\hline Moisture $(\mathrm{g})$ & 71.50 & 77.30 \\
\hline Protein $(\mathrm{g})$ & 26.15 & 16.60 \\
\hline Energy (Kcalories) & 129 & 117 \\
\hline Fat (total lipids) $(\mathrm{g})$ & 2.65 & 5.10 \\
\hline Saturated fat $(\mathrm{g})$ & 0.94 & 23.60 \\
\hline Minerals & & 80 \\
\hline Calcium $(\mathrm{mg})$ & 14 & 219 \\
\hline Magnesium $(\mathrm{mg})$ & 34 & 1.76 \\
\hline Phosphorus $(\mathrm{mg})$ & 204 & 3.71 \\
\hline Potassium $(\mathrm{mg})$ & 308 & 372 \\
\hline Sodium $(\mathrm{mg})$ & 56 & \\
\hline Vitamins & & 0.49 \\
\hline Thiamin, B1 $(\mathrm{mg})$ & 0.093 & 98.4 \\
\hline Niacim, B3 $(\mathrm{mg})$ & 4.78 & 0.63 \\
\hline Folic acid $(\mathrm{mg})$ & & $100 \mathrm{f}$ \\
\hline
\end{tabular}

Table 1: Proximate nutrient composition of catfish and tilapia (per 100g) (Afolabi et al,1984;Ogbonnaya and Ibrahim,2009) [2,5].

*Corresponding author: Burubai W, Department of Agricultural \& Environmental Engineering, Faculty of Engineering, Niger Delta University, P.M.B. 071, Wilberforce Island, Yenagoa, Bayelsa State, Nigeria, Tel: 800-5551212; E mail: ebiburu@yahoo.com

Received February 24, 2014; Accepted March 24, 2014; Published April 03, 2014

Citation: Burubai W, Amber B (2014) Microwave Heating-Dependent Properties of Tilapia (Oreochromis niloticus) and Catfish (Clarias gariepirus). J Food Process Technol 5: 315. doi:10.4172/2157-7110.1000315

Copyright: (c) 2014 Burubai W, et al. This is an open-access article distributed under the terms of the Creative Commons Attribution License, which permits unrestricted use, distribution, and reproduction in any medium, provided the original author and source are credited. 


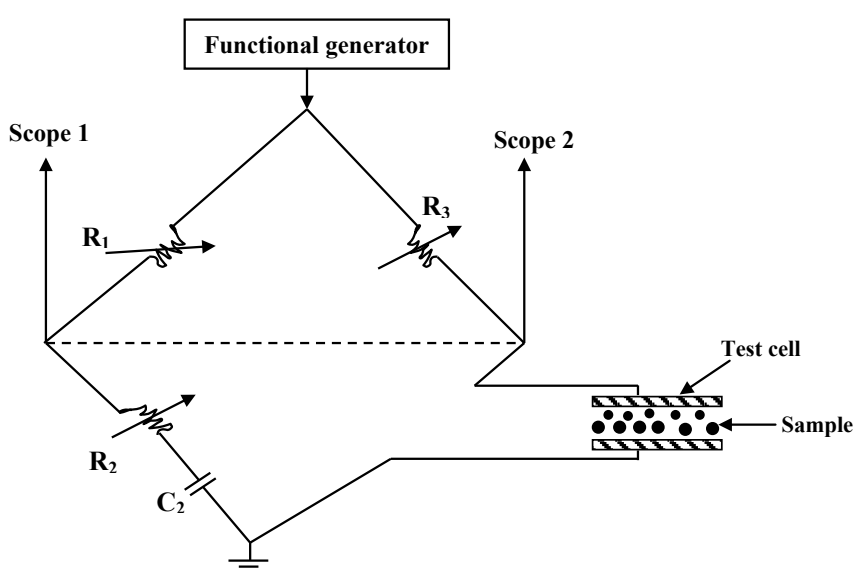

Figure 1: A modified Wheatstone bridge circuit.

\section{Materials and Methods}

\section{Sample preparation}

Ten marketable- sized each of Catfish and Tilapia was purchased from a local market in Amassoma, Bayelsa state in October, 2012 to evaluate the influence of moisture and frequency on the dielectric properties. The fish were prepared (eviscerated, beheaded and washed), and muscles (fillets) cut out and the initial moisture content of both fish species determined using the oven method as recommended by ASAE standard [11]. After drying at $70^{\circ} \mathrm{C}$ for 24 hours, a constant weight was achieved and moisture content determined. Each species of fish was then homogenized using a kitchen blender. To determine the effect of moisture on the parameters under investigation, the homogenized test samples of both fish were conditioned to different moisture levels of $6.2 \%, 8.4 \%, 10.0 \%, 12.2 \%, 14.0 \%$, and $16.5 \%$ dry basis, using equation (1).

$$
M w=W t\left(\frac{M f-M i}{100-M f}\right)
$$

Where

$$
\begin{aligned}
\mathrm{Mw} & =\text { mass of water added to sample, } \mathrm{g} \\
\mathrm{Wt} & =\text { mass of the fish sample, } \mathrm{g} \\
\mathrm{Mi} & =\text { initial moisture content of fish sample, } \% \\
\mathrm{Mf} & =\text { expected final moisture of fish sample, } \%
\end{aligned}
$$

\section{Apparatus used}

The equipment used for the experimentation consists of an Aditeg function generator (FG 8030), Matrix Oscilloscope (MOS-620CH), Fluke Industrial True - rus Multimeter (Series 87V), Camry Digital scale (EK 5350), a modified Wheatstone bridge circuit and Digital Caliper. The function generator was used to produce an alternating current with variable magnitude and frequency whereas the matrix oscilloscope monitored and displayed the resultant sinusoidal wave forms. The multimeter was used for measuring the resistance and capacitance of the variable resistors and the samples. The modified Wheatstone bridge circuit and the equations employed are given below.

\section{Dielectric Constant, $\varepsilon^{1}$}

$\varepsilon^{1}=\frac{1}{2 \pi f \varepsilon_{0}} \times \frac{L}{A} \times \frac{X_{s}}{R_{s}^{2}+X_{s}^{2}}$

\section{Dielectric loss factor, $\varepsilon^{11}$}

$$
\varepsilon^{11}=\frac{1}{2 \pi f \varepsilon_{0}} \times \frac{L}{A} \times \frac{R_{s}}{R_{5}^{2}+X_{5}^{2}}
$$

\section{Where}

$\mathrm{L}=$ separation distance between sample, holders, $\mathrm{cm}$

$\mathrm{A}=$ crossectional area of sample holder, $\mathrm{cm}^{2}$

$\mathrm{R}_{\mathrm{s}}=$ resistance of sample, $\Omega$

$\mathrm{X}_{\mathrm{s}}=X_{s}=\frac{1}{2 \pi f C_{5}}=$ capacitive reactance of the sample

$\mathrm{C}_{\mathrm{s}}=$ capacitance of the sample, $\mathrm{pF}=C_{2}\left(\frac{R_{1}}{R_{3}}\right)$

\section{Loss tangent, $\delta$}

$$
\tan \delta=\frac{\varepsilon^{11}}{\varepsilon^{1}}
$$

\section{Effective Conductivity, $\sigma$}

$$
\sigma=\omega \varepsilon_{0} \varepsilon^{11}\left(\frac{s}{m}\right)
$$

where

$$
\begin{aligned}
& f=\text { measuring frequency, } \mathrm{Hz} \\
& \varepsilon_{0}=\text { permittivity of free space }\left(8.85 \times 10^{-12} \mathrm{f} / \mathrm{m}\right)
\end{aligned}
$$

\section{Procedure}

The fundamental principle underlying the experimentation is the capacitance technique (impedance method). It is based on the fact that when biological materials are incorporated into an electric circuit, they act as resistors and capacitors, or, more commonly, as a combination of resistors and capacitors [12]. Thus, the Wheatstone bridge and entire apparatus was set up as shown in Figure 1 above and $150 \mathrm{~g}$ of homogenized sample was drawn from each of the predetermined moisture levels and placed in the test cell. A weight of $2 \mathrm{~kg}$ was then placed on the platform of the test stand to ensure proper contact between the sample and holder. Measurements were then made of the distance separating the sample in the test stand. To ascertain the effect of moisture, the function generator was set to the desired frequency of $1 \mathrm{KHz}$ and the a.c. sine wave output adjusted until amplitude of 2 volts was obtained. The bridge circuit was then balanced by adjusting $\mathrm{R}_{1}$ and $\mathrm{R}_{2}$ until the peak amplitudes of the two sine waves occurs at the same ordinate value. The function generator was then disconnected from the circuit and resistance measurements of $R_{1}, R_{2}$ and $R_{3}$ were taken. Capacitance, $\mathrm{C}_{2}$ was then disconnected from the circuit and its capacitance determined. Three replications were made and the average recorded and used to calculate the desired parameters using the equations above.

Similarly, to determine the influence of frequency on the parameters under study, four frequency levels of $1 \mathrm{KHz}, 10 \mathrm{KHz}, 100 \mathrm{KHz}$ and 1 $\mathrm{MHz}$ were selected and investigated at a moisture level of $12.2 \%$ dry basis. $150 \mathrm{~g}$ sample was drawn from both Catfish and Tilapia specimens and placed in the test cell and the above test procedures repeated at the desired frequency levels

\section{Results and Discussions}

Tables 2 and 3 below reveal respectively the effect of moisture content on the dielectric properties of Tilapia and Catfish muscles. 
Citation: Burubai W, Amber B (2014) Microwave Heating-Dependent Properties of Tilapia (Oreochromis niloticus) and Catfish (Clarias gariepirus). J Food Process Technol 5: 315. doi:10.4172/2157-7110.1000315

Page 3 of 7

\section{Effects of moisture content on resistance, $\Omega$}

The electrical resistance of Tilapia muscles generally decreased with increase in moisture content as indicated in Table 2. At 6.2\% moisture level, a corresponding resistance of $9.56 \Omega$ was recorded. This value steadily decreased to $3.13 \Omega$ at $16.5 \%$ moisture level. Similarly, Catfish muscle also showed a negative trend with moisture increase as depicted in Table 3. At $6.2 \%$ moisture level, a resistance value of $11.88 \Omega$ was observed. The resistance sharply reduced to $6.53 \Omega$ at $16.5 \%$ moisture content. This decrease in electrical resistance at higher moisture levels in both species of fish could be attributed to the fact that, at higher moisture, more polarization of water molecules occur and this permits the free flow of electrons. These findings are closely related to the works of Mahmoud and Reza [6], and the mathematical dependence of resistance on moisture content for Tilapia and Catfish muscles are as shown in Figure 2 below.

\section{Effects of moisture content on dielectric constant, $\varepsilon^{1}$}

As shown in Table 2, dielectric constant of Tilapia increased with increase in moisture levels. The dielectric constant changed from 2.19 to 10.97 at $6.2 \%$ to $16.5 \%$ moisture levels respectively. A similar behavior was noted with Catfish muscle as dielectric constant increased from 1.35 to 54.14 at corresponding moisture levels of $6.2 \%$ and $16.5 \%$ respectively. This positive relationship between dielectric constant and moisture content for both species of fish implies that fish muscles can conveniently store a large quantity of electromagnetic energy, which is the precursor to microwave drying. Moreover, the increase in dielectric constant at higher moisture level is believed to be dictated by more polarization of water and ionization of bound salts responsible for the mobility of water molecules. The results presented here agree with that of Sipahioglu and Baringer [9] and Figure 3 and the resulting regression equations show the relationship between moisture level and dielectric constant for Catfish and Tilapia.

\section{Effect of moisture content on dielectric loss factor, $\varepsilon^{11}$}

Generally, dielectric loss factor, $\varepsilon^{11}$, of both fish species appears to be positively correlated to moisture increases as demonstrated in Tables 2 and 3. For Tilapia and at $6.2 \%$ moisture level, a loss factor of

\begin{tabular}{|c|c|c|c|c|c|c|c|c|c|c|c|c|}
\hline MC (\%) & Sep. Distance $(\mathrm{cm})$ & Area $\left(\mathrm{cm}^{2}\right)$ & Freq. (KHz) & $R_{1}(\Omega)$ & $R_{2}(\Omega)$ & $R_{3}(\Omega)$ & $C_{2}(p F)$ & $\mathbf{R}_{\mathrm{s}}(\Omega)$ & $C_{s}(p F)$ & $X_{5}(\Omega)$ & $\varepsilon^{1}$ & $\varepsilon^{11}$ \\
\hline 6.2 & 1.82 & 24.53 & 1.0 & 106.2 & 37.25 & 27.25 & 269 & 9.56 & 1.048 & 0.000152 & 2.195 & 0.10 \\
\hline 8.4 & 1.11 & 24.53 & 1.0 & 110.4 & 29.50 & 27.25 & 283 & 7.28 & 1.147 & 0.000139 & 2.137 & 11.19 \\
\hline 10.0 & 1.10 & 24.53 & 1.0 & 95.9 & 24.03 & 27.25 & 213 & 6.83 & 0.750 & 0.000212 & 3.661 & 11.79 \\
\hline 12.2 & 1.08 & 24.53 & 1.0 & 104.8 & 20.25 & 27.25 & 273 & 5.27 & 0.273 & 0.000383 & 5.61 & 15.28 \\
\hline 14.0 & 1.03 & 24.53 & 1.0 & 111.2 & 16.57 & 27.25 & 278 & 4.06 & 1.134 & 0.000140 & 6.72 & 19.48 \\
\hline 16.5 & 1.00 & 24.53 & 1.0 & 108.0 & 12.4 & 27.25 & 274 & 3.13 & 1.086 & 0.000146 & 10.97 & 23.42 \\
\hline
\end{tabular}

Table 2: Effect of moisture level on dielectric properties of Tilapia.

\begin{tabular}{|c|c|c|c|c|c|c|c|c|c|c|c|c|}
\hline MC (\%) & Sep. Distance $(\mathrm{cm})$ & Area $\left(\mathrm{cm}^{2}\right)$ & Freq. (KHz) & $R_{1}(\Omega)$ & $R_{2}(\Omega)$ & $R_{3}(\Omega)$ & $C_{2}(p F)$ & $R_{\mathrm{s}}(\Omega)$ & $C_{s}(p F)$ & $X_{5}(\Omega)$ & $\varepsilon^{1}$ & $\varepsilon^{11}$ \\
\hline 6.2 & 1.22 & 24.53 & 1.0 & 112.0 & 33.06 & 40.23 & 268 & 11.88 & 0.75 & 0.00021 & 0.35 & 75.28 \\
\hline 8.4 & 1.62 & 24.53 & 1.0 & 67.3 & 23.67 & 40.23 & 269 & 14.15 & 0.45 & 0.00035 & 2.08 & 83.92 \\
\hline 10.0 & 1.30 & 24.53 & 1.0 & 103.4 & 18.19 & 40.23 & 268 & 7.08 & 0.69 & 0.00023 & 4.38 & 134.60 \\
\hline 12.2 & 1.57 & 24.53 & 1.0 & 93.2 & 13.91 & 40.23 & 273 & 6.00 & 0.63 & 0.00025 & 7.99 & 19.81 \\
\hline 14.0 & 1.60 & 24.53 & 1.0 & 102.5 & 17.30 & 40.23 & 277 & 6.79 & 0.11 & 0.00145 & 36.89 & 172.73 \\
\hline 16.5 & 1.80 & 24.53 & 1.0 & 107.2 & 17.41 & 40.23 & 280 & 6.53 & 0.75 & 0.000049 & 54.15 & 168.38 \\
\hline
\end{tabular}

Table 3: Effect of moisture level on dielectric properties of Catfish.

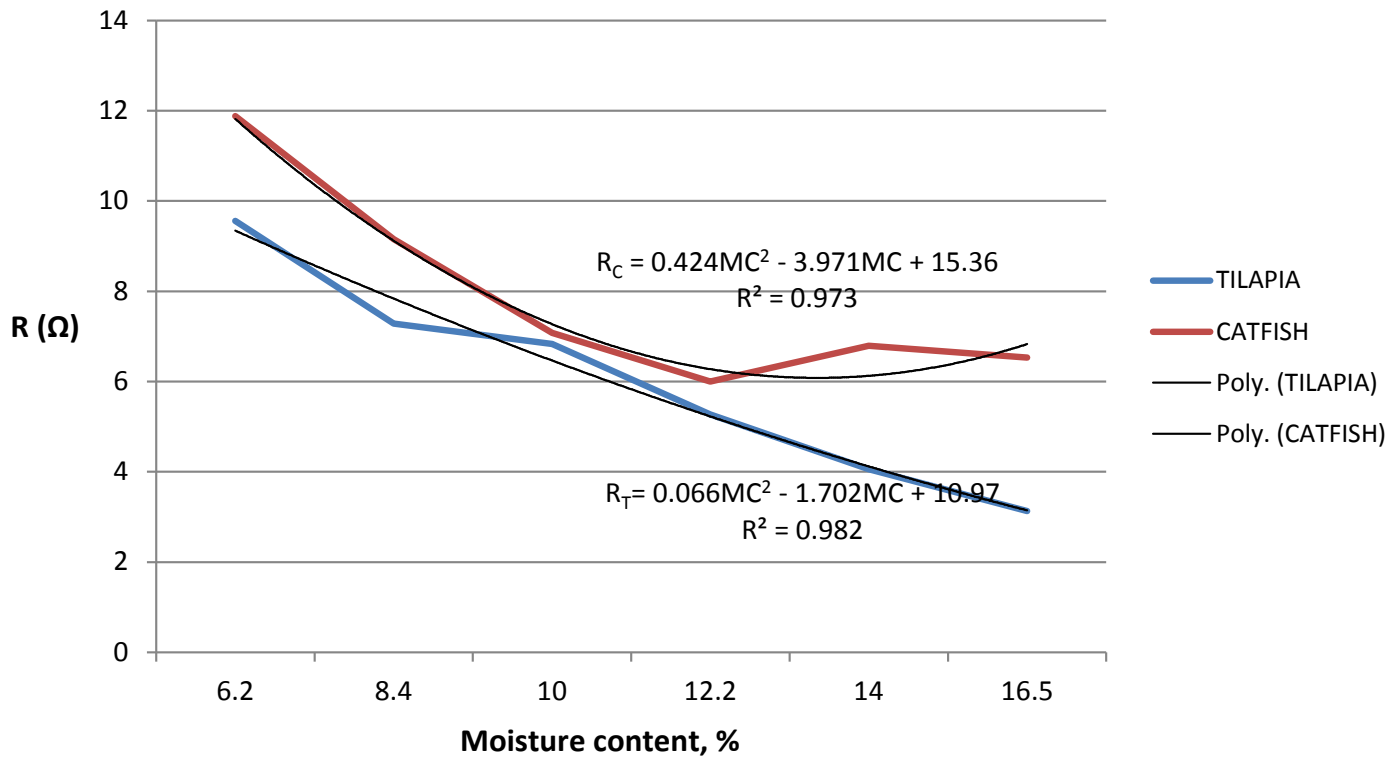

Figure 2: Effect of moisture on the resistance of Tilapia and Catfish muscles. 
Citation: Burubai W, Amber B (2014) Microwave Heating-Dependent Properties of Tilapia (Oreochromis niloticus) and Catfish (Clarias gariepirus). J Food Process Technol 5: 315. doi:10.4172/2157-7110.1000315

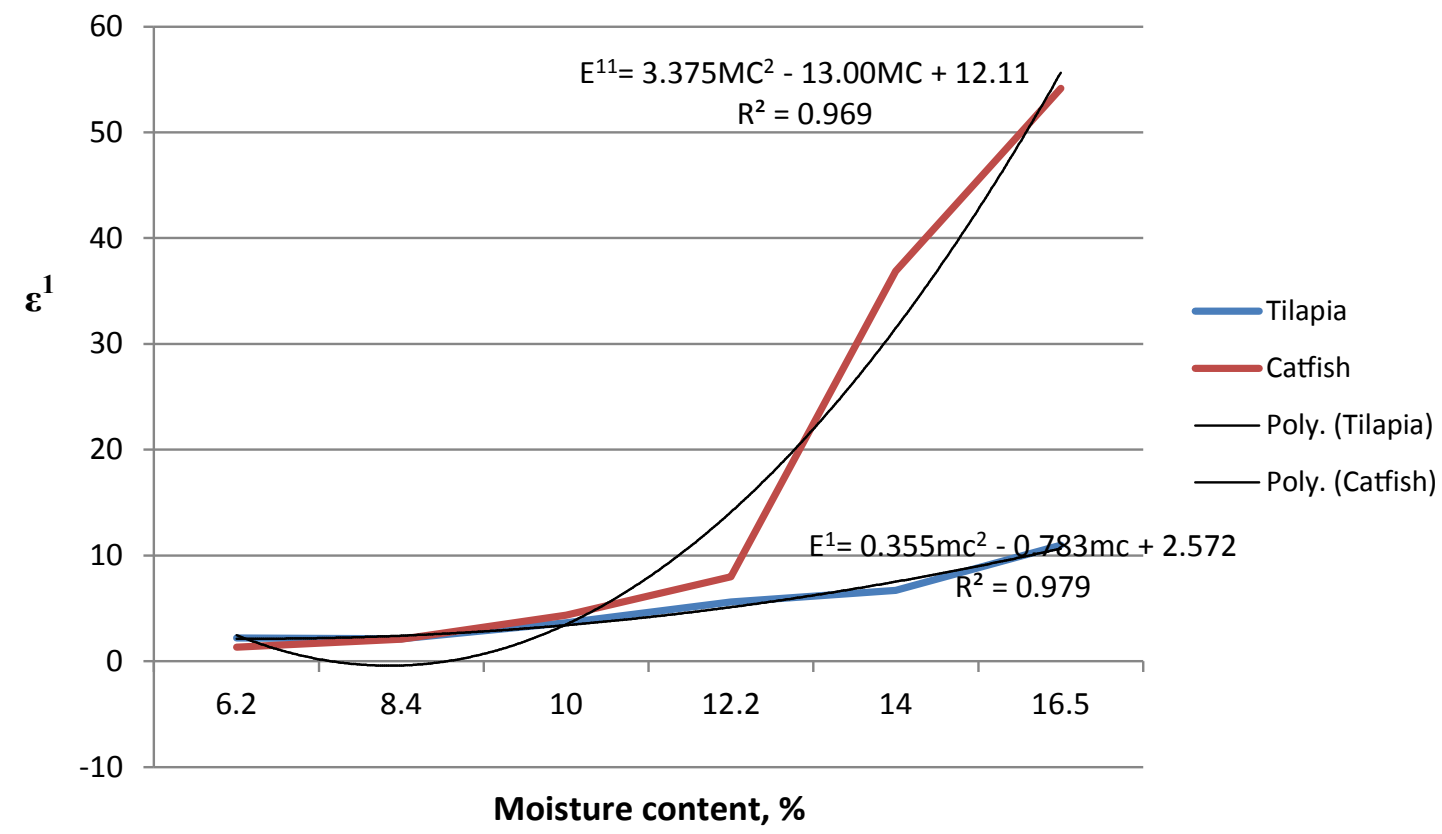

Figure 3: Effect of moisture on dielectric constant of Tilapia and Catfish muscles.

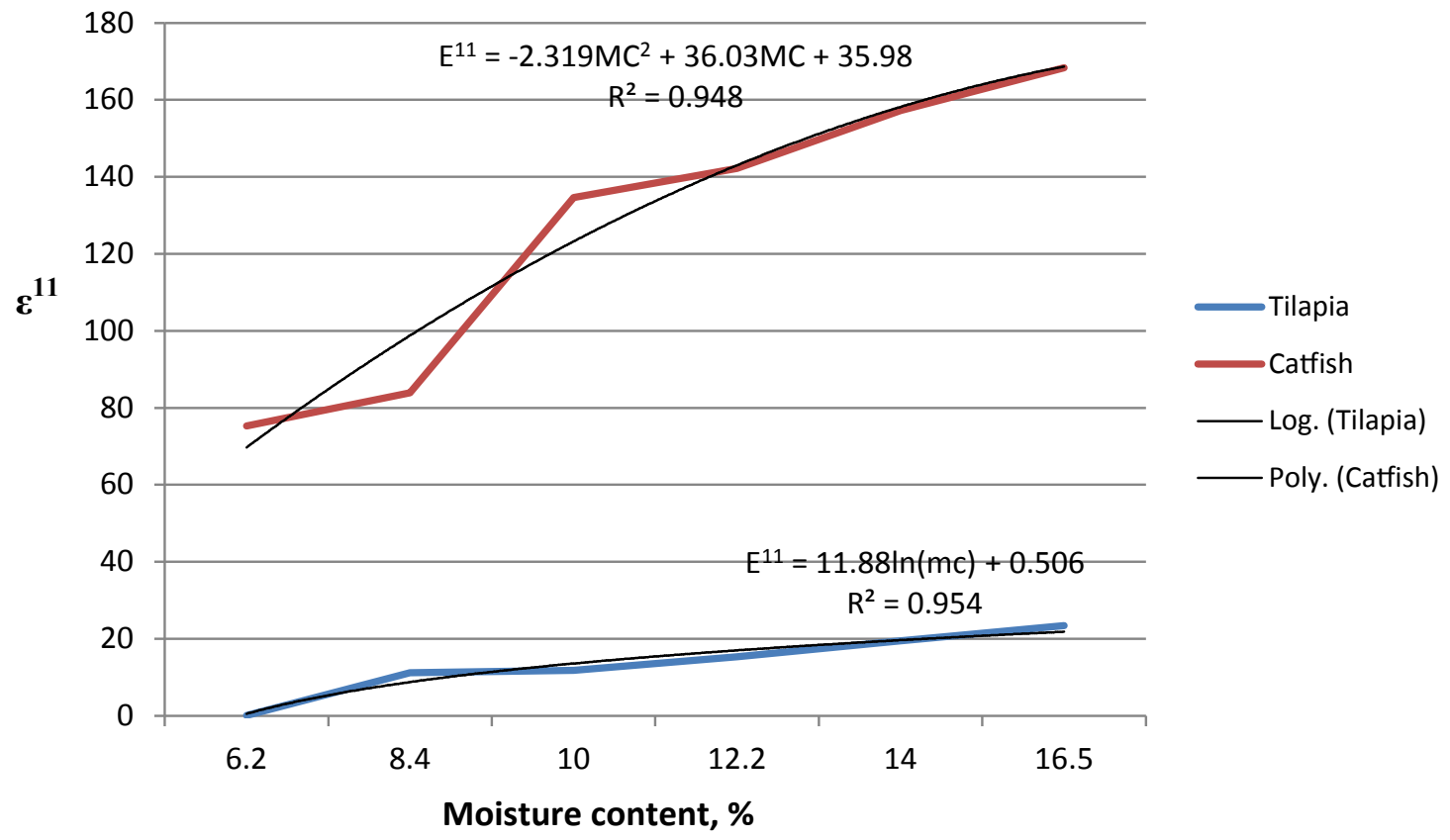

Figure 4: Effect of moisture on loss factor of Tilapia and Catfish muscles.

0.10 was recorded. Loss factor then increased consistently to 23.4 at $16.5 \%$ moisture level. Catfish muscle also exhibited a similar behavior as its loss factor value increased from 75.28 to 168.38 at the respective moisture levels $6.2 \%$ to $16.5 \% \mathrm{db}$. This behavior of the fish muscles could be attributed to dipolar relaxation and ionic conduction of water in the muscles. A further explanation is that, the water molecules in the muscles tends to follow the electric field as they alternate at the present frequency and these rotations of water molecules produce heat. Therefore, at $16.5 \%$ moisture, more water molecules are set free to undergo rotation. Kamil and Ahmet [13] discovered a similar behavior for pea and Figure 4 presents the trend between moisture content and loss factor for Tilapia and Catfish muscles.

The influence of frequency of oscillation on the dielectric properties of Tilapia and Catfish muscles is presented on Tables 4 and 5 below.

\section{Effect of frequency on electrical resistance, $\Omega$}

Electrical resistance of biomaterials, which is known to be the 
Citation: Burubai W, Amber B (2014) Microwave Heating-Dependent Properties of Tilapia (Oreochromis niloticus) and Catfish (Clarias gariepirus). J Food Process Technol 5: 315. doi:10.4172/2157-7110.1000315

Page 5 of 7

\begin{tabular}{|c|c|c|c|c|c|c|c|c|c|c|c|c|}
\hline Frequency $\mathbf{( H z )}$ & Sep. Distance $\mathbf{( c m )}$ & Area $\left.\mathbf{( c m}^{2}\right)$ & $\mathbf{R}_{\mathbf{1}}(\mathbf{\Omega})$ & $\mathbf{R}_{\mathbf{2}}(\mathbf{\Omega})$ & $\mathbf{R}_{\mathbf{3}}(\boldsymbol{\Omega})$ & $\mathbf{C}_{\mathbf{2}}(\mathbf{p F})$ & $\mathbf{R}_{\mathbf{s}}(\mathbf{\Omega})$ & $\mathbf{C}_{\mathbf{s}}(\mathbf{p F})$ & $\mathbf{X}_{\mathbf{s}}(\mathbf{\Omega})$ & $\boldsymbol{\varepsilon}^{\mathbf{1}}$ & $\boldsymbol{\varepsilon}^{\mathbf{1 1}}$ \\
\hline $1 \mathrm{KHz}$ & 1.64 & 24.53 & 65.4 & 15.45 & 26.83 & 275 & 6.34 & 0.670 & 0.000238 & 174.63 & 189.641 \\
\hline $10 \mathrm{KZz}$ & 1.64 & 24.53 & 66.5 & 15.94 & 26.83 & 280 & 6.43 & 0.694 & 0.0000229 & 0.10 & 18.698 \\
\hline $100 \mathrm{Kz}$ & 1.64 & 24.53 & 70.6 & 15.77 & 26.83 & 276 & 5.99 & 0.726 & 0.0000021 & 0.0007 & 2.007 \\
\hline $1 \mathrm{MHz}$ & 1.64 & 24.53 & 108.0 & 12.4 & 26.83 & 274 & 3.08 & 1.103 & 0.00000014 & 0.000018 & 0.39 \\
\hline
\end{tabular}

Table 4: Effect of frequency variations on dielectric properties of Tilapia muscles.

\begin{tabular}{|c|c|c|c|c|c|c|c|c|c|c|c|}
\hline Frequency $(\mathrm{Hz})$ & Sep. Distance $(\mathbf{c m})$ & Area $\left(\mathrm{cm}^{2}\right)$ & $R_{1}(\Omega)$ & $R_{2}(\Omega)$ & $R_{3}(\Omega)$ & $C_{2}(p F)$ & $R_{s}(\Omega)$ & $C_{s}(p F)$ & $\mathrm{X}_{\mathrm{s}}(\Omega)$ & $\varepsilon^{1}$ & $\varepsilon^{11}$ \\
\hline $1 \mathrm{KHz}$ & 1.30 & 24.53 & 112.0 & 33.0 & 26.96 & 265 & 7.94 & 1.101 & 0.000145 & 2.185 & 150.017 \\
\hline $10 K Z z$ & 1.30 & 24.53 & 132.6 & 32.13 & 26.96 & 269 & 6.53 & 1.323 & 0.000012 & 0.027 & 145.93 \\
\hline $100 \mathrm{Kz}$ & 1.30 & 24.53 & 112.0 & 32.9 & 26.96 & 269 & 5.92 & 1.120 & 0.00000142 & 0.00022 & 120.3 \\
\hline $1 \mathrm{MHz}$ & 1.30 & 24.53 & 112.0 & 33.06 & 26.96 & 268 & 4.96 & 1.134 & 0.00000014 & 0.00000198 & 119.01 \\
\hline
\end{tabular}

Table 5: Effect of frequency variations on dielectric properties of Catfish muscle.

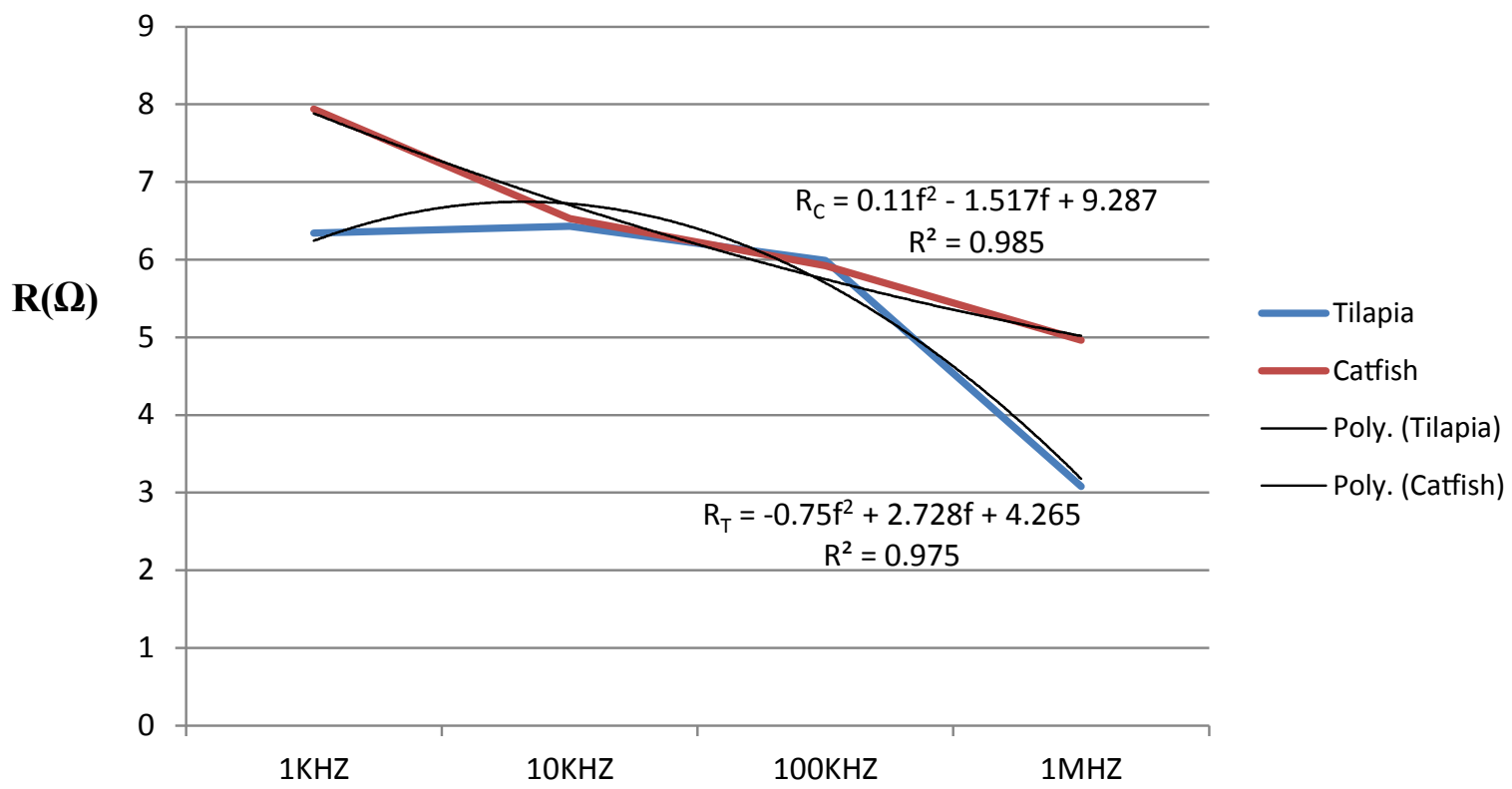

Frequency

Figure 5: Effect of frequency on electrical resistance of Tilapia and catfish muscles.

opposition to free flow of electrons, is largely dependent on the frequency of oscillations. Therefore, it's clear from Table 4 that resistance of Tilapia muscles decreases with increase in frequency level. Resistance value of $6.34 \Omega$ was noted at $1 \mathrm{KHz}$ and then decline to $3.08 \Omega$ at $1 \mathrm{MHz}$. For Catfish, $7.94 \Omega$ and $4.96 \Omega$ were observed for the respective frequency levels of $1 \mathrm{KHz}$ and $1 \mathrm{MHz}$. The decrease in resistance at higher frequency level for both fish is a desired effect in microwave heating, and could be attributed to the fact that as frequency increases, the number and speed of oscillations increases, thereby overcoming with ease, any resistance posed by the fish muscles. Figure 5 is an indication of the dependence of electric resistance of both fish muscles on frequency of oscillation.

\section{Effect of frequency on dielectric constant, $\varepsilon^{1}$}

As shown in Table 4 and 5, the dielectric constant of both Tilapia and Catfish reveals a negative relationship with frequency changes. For Tilapia muscles, dielectric constant decreased sharply from 174.63 to 0.000018 at corresponding frequencies of $1 \mathrm{KHz}$ and $1 \mathrm{MHz}$ respectively. Catfish muscle also displayed a similar behaviour as dielectric constant values changed from 2.185 to 0.00000198 at $1 \mathrm{KHz}$ and $1 \mathrm{MHz}$. This implies that at low frequencies, the water molecules can steadily follow the changes of the electric field, and this, perhaps, is the reason why dielectric constant is at its peak. At higher frequencies the dipoles are unable to swiftly trail the field reversals, thus decreasing the dielectric constant value. These findings agree with that of Green [8] and the dependence of dielectric constant on frequency of oscillation on both fish is as indicated in Figure 6 .

\section{Effect of frequency on dielectric loss factor, $\varepsilon^{11}$}

Biological materials are viscoelastic in nature. This implies that they contain reasonable amounts of water molecules and therefore, when subjected to higher frequencies, the water molecules rotate in the electric fields and generate heat. This heating effect is the desired characteristics for drying operations. For Tilapia and at a frequency of $1 \mathrm{KHz}$, a loss factor of 189.64 was noted. The loss factor value then changed to 0.39 at a corresponding frequency of $1 \mathrm{MHz}$. Similarly, Catfish muscles gave loss factor readings of 150.02 to 119.01 at frequency changes of $1 \mathrm{KHz}$ to $1 \mathrm{MHz}$ respectively. Results presented here concur with the works of Sipahioglu and Barringer [9] and the 
Citation: Burubai W, Amber B (2014) Microwave Heating-Dependent Properties of Tilapia (Oreochromis niloticus) and Catfish (Clarias gariepirus). J Food Process Technol 5: 315. doi:10.4172/2157-7110.1000315

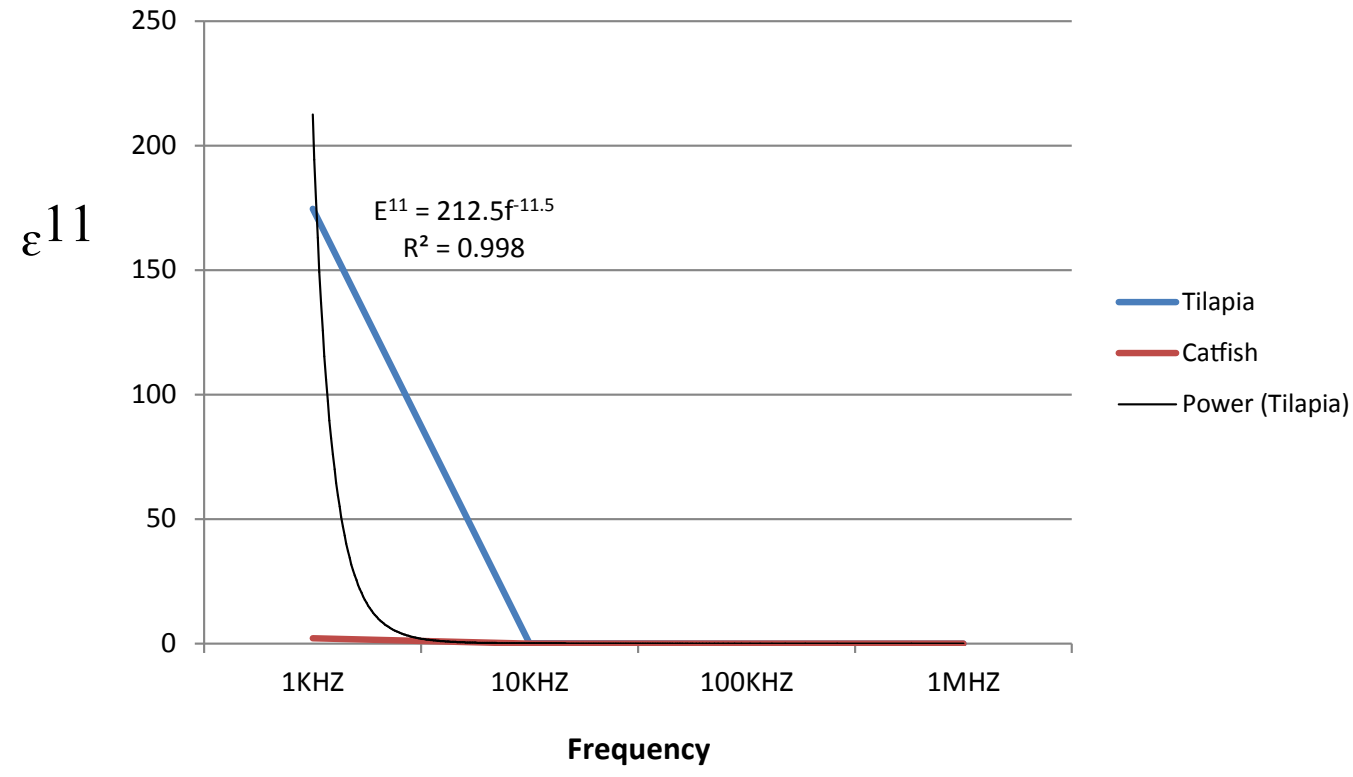

Figure 6: Effect of frequency on dielectric constant on Tilapia and Catfish muscles.

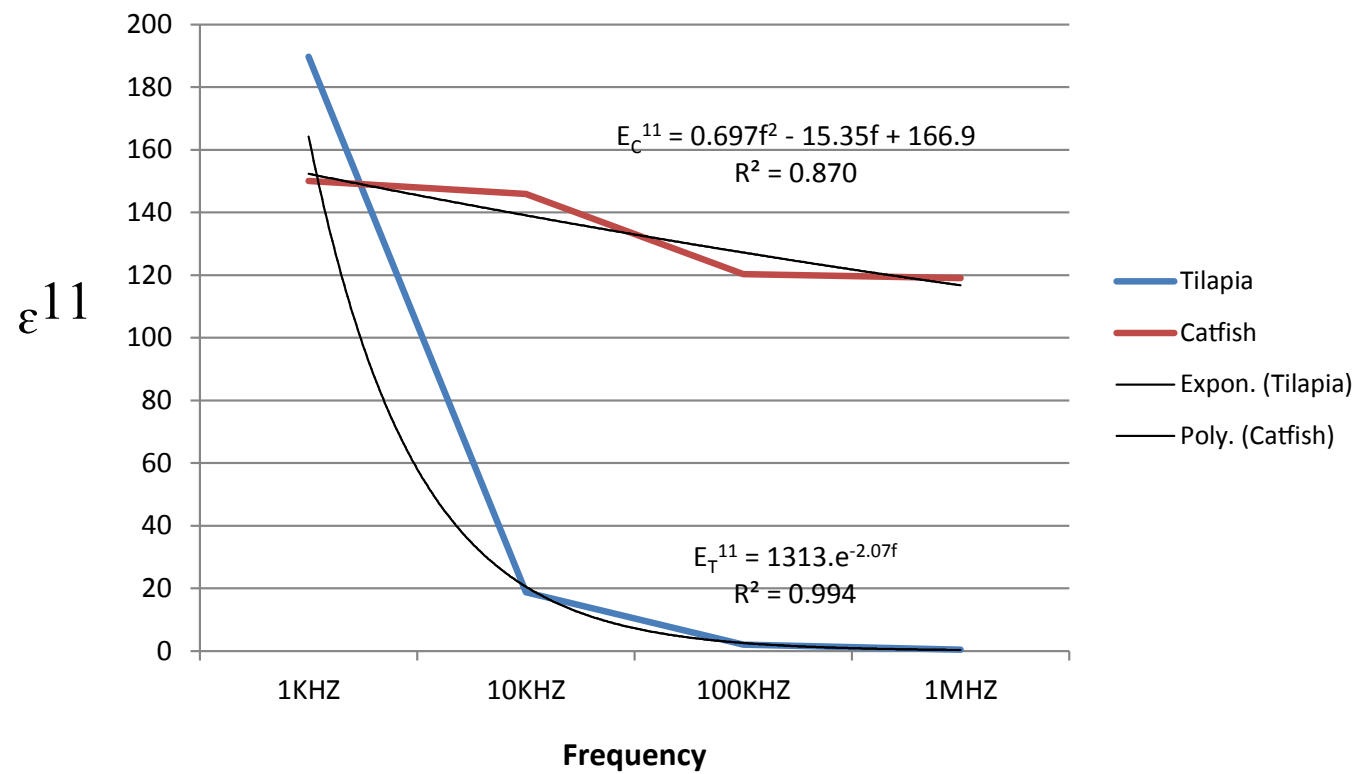

Figure 7: Effect of frequency on loss factor of Tilapia Catfish muscles.

relationship between loss factor and frequency for both Tilapia and Catfish is indicated in Figure 7.

\section{Conclusion}

Some microwave heating-dependent properties of Tilapia and Catfish were studied. Results show that moisture content and frequency of oscillation has significant influence on these properties. Therefore, information provided here is recommended for determining the microwave drying rates and times for both species of fish.

\section{References}

1. Food and Agricultural Organization, (FAO) (1999) World production of fish crustaceans and molluscs by major fishing areas. Fisheries Department, FAO.
2. Afolabi OA, Arawomo O, Oke L (1984) Quantity changes of Nigerian Traditional processed fresh water species: 1 Nutritive and Organoleptic changes. J Food Technol 19: 333-340.

3. Eves A, Brown R (1993) The effect of traditional drying processes on the nutritional values of fish. Tropical Science 33: 183-189.

4. Eyo AA (2001) Fish Processing Technology in the Tropics. National Institute for Freshwater Fisheries Research (NIFFR). New Bussa, Nigeria.

5. Ogbonnaya C, Ibrahim M (2009) Effect of drying methods on the proximate composition of Catfish (Clarias garienpinus). World Journal of Agricultural Sciences 5: 114-116.

6. Mahmoud S, Reza A(2011) Moisture-dependent dielectric properties of pea. Journal of American Science 7: 60-64.

7. Afzal S, Mousavi S, Khademi M (2010) Estimation of leaf moisture content by 
Citation: Burubai W, Amber B (2014) Microwave Heating-Dependent Properties of Tilapia (Oreochromis niloticus) and Catfish (Clarias gariepirus). J Food Process Technol 5: 315. doi:10.4172/2157-7110.1000315

Page 7 of 7

measuring capacitance. Journal of Agricultural Science and Technology 12 : 339- 346 .

8. Green AD (1997) Measurement of the dielectric properties of chedder cheese. J Microwave Power Electromagn Energy 32: 16-27.

9. Sipahioglu O, Barringer S (2003) Dielectric Properties of fruits and vegetables as a function of ash and moisture content. J Food Sci 68: 234-239.

10. Burubai W, Meindinyo R (2013) Effects of moisture and frequency variations on the dielectric properties of African Nutmeg (Monodora myristica) seeds. International Agricultural Engineering Journal 22: 20-26.
11. ASAE Standard (2000) S368.4 (10th Edn) Compression Test of Food Materials of Convex Shapes. ASAE Press, St. Joseph, MI.

12. Rao M, Rizvi S, Datta AK (2005) Engineering Properties of Foods. (3 $3^{\text {rd }}$ Edition), CRC Press.

13. Kamil S, Ahmet C (2005) Dielectric properties of Opium Poppy Seed. Tarim Bilimari Dergisi 11: 104-109. 